\title{
Idiopathic central precocious puberty associated with an enlarged pituitary gland
}

\author{
S Pathmanathan ${ }^{1}$, Navoda Atapattu ${ }^{2}$, N P Somasundaram ${ }^{3}$, K S H de Silva \\ Sri Lanka Journal of Diabetes, Endocrinology and Metabolism 2014; 4: 35-39
}

\begin{abstract}
Precocious puberty is a rare condition characterized by the development of secondary sexual characteristics before the median age for the sex. We report a 5 year and 7 month old girl who presented to us with precocious puberty who had a large anterior pituitary for the age.
\end{abstract}

Key words: central precocious puberty (CPP), magnetic resonance imaging (MRI), pituitary gland

\section{Introduction}

Precocious puberty in girls is defined as the development of secondary sexual characteristics before the age of eight years. There are two types, gonadotrophin dependent, or gonadotrophin independent. Gonadotrophin dependent precocious puberty is due to the premature activation of the hypothalamo-pituitary-ovarian axis, also known as central precocious puberty (CPP) (1). $\mathrm{CPP}$ in girls is idiopathic in the majority of cases (2).

Magnetic resonance imaging (MRI) of the head with special attention to the hypothalamo pituitary region is indicated in patients with CPP to look for a tumor or an intracerebral lesion after hormonal studies indicate a diagnosis of central precocious puberty $(3,4)$. The size and shape of the normal pituitary gland vary considerably which is also affected by age, sex, and hormonal environment $(5,6,7)$. The increase in pituitary height and volume during puberty is well known $(8,9)$. This increase during puberty is related to the changes in the endocrine hormone secretion during puberty specially due to the hyper-secretion of luteinizing hormone ( $\mathrm{LH}$ ) during this period $(10,11)$. These morphological changes can mimic pituitary adenomas causing confusion in the diagnostic process. Therefore careful evaluation by a multidisciplinary team and correct interpretation of the imaging is important in the management of CPP before appropriate treatment is instituted.

We describe a child with central precocious puberty whose MRI of the brain was suggestive of an anterior pituitary tumour without mass effect. After careful evaluation and interpretation it was concluded that the increase in size in the pituitary gland is a normal variation due to the premature activation of the hypothalamopituitary-ovarian axes.

\section{Case presentation}

A 5 year and 7 month old baby girl was referred to our pediatric endocrinology unit for evaluation of bilateral breast enlargement and growth of pubic hair of six months duration followed by one episode of vaginal spotting, initially noticed one week prior to her presentation. Her birth history was unremarkable and her growth and development were normal until 3 years of age. From 3 years of age her parents noticed she was growing taller than her elder sibling who was 1 year and 5 months older than her. She was noticed to be crossing her centiles in both height and weight at well baby clinics (Figure 1). There was no history of early morning headache, vomiting, visual disturbances, fits or past history of cranial irradiation. There was no family history of endocrinological disorders or precocious puberty. At presentation, our patient was an alert child. Her height was $132 \mathrm{~cm}(>97$ th percentile) and $34.8 \mathrm{~kg}$ in weight ( $>97$ th percentile). Her vital signs were normal. She had normal ocular, thyroid and cardiorespiratory examinations. She had Tanner stage III breast development and pubic hair of Tanner stage II .

Her bone age was 11 years at a chronological age of 5 years and 7 months. USS abdomen revealed normal ovaries but the uterus was large for age $(5.8 \times 2.7 \times 2.2 \mathrm{~cm})$

\footnotetext{
${ }^{1}$ Senior Registrar in Endocrinology, National Hospital of Sri Lanka, Colombo, ${ }^{2}$ Consultant Paediatric Endocrinologist, Lady Ridgeway Hospital, Colombo, ${ }^{3}$ Consultant Endocrinologist, National Hospital of Sri Lanka, Colombo, ${ }^{4}$ Consultant Paediatrician, Lady Ridgeway Hospital and Professor in Paediatrics, Faculty of Medicine, University of Colombo, Sri Lanka.
} 
and adrenals were normal. Her haematological and biochemical parameters were within normal limits. Hormonal assay revealed the following: 8 am serum follicle stimulating hormone (FSH) and LH were $8.24 \mathrm{mIU} / \mathrm{ml}$ (follicular phase- $2.8-11.3$ ) and $2.08 \mathrm{mIU} / \mathrm{ml}$ (follicular phase - 1.1 -11.6) respectively while midnight FSH and LH were $3.85 \mathrm{mIU} / \mathrm{ml}$ (follicular phase - 2.8 -11.3) and 3.77 $\mathrm{mIU} / \mathrm{ml}$ (follicular phase - 1.1 -11.6) respectively. Serum estradiol $59 \mathrm{pg} / \mathrm{ml}$ (39 -189), 3rd gen TSH - $2.29 \mathrm{mIu} / \mathrm{ml}$ (6y - 0.34-6.0), 8 am serum cortisol - $13.8 \mu \mathrm{g} / \mathrm{dl}$ (2-6 years 1-26), serum prolactin - $8.32 \mathrm{ng} / \mathrm{ml}$ (6-10 years $-1.2-11.4)$ and serum Insulin like Growth Factor (IGF 1) $-628 \mathrm{ng} / \mathrm{ml}$ (6yr - 52-297) (11 yr - 111 -551). Hormonal assay revealed elevated levels of serum FSH, LH, and serum estradiol confirming the clinical diagnosis of CPP. Interestingly her serum IGF-1 was elevated even when compared to her advanced bone age.

Magnetic resonance imaging (MRI) of the brain was reported to have an early anterior pituitary tumour without mass effect (Figure $2 \& 3$ ). Considering the elevated serum IGF level and the MRI findings the patient underwent a standard $75 \mathrm{mg}$ oral glucose tolerance test (OGTT) (Table 1).

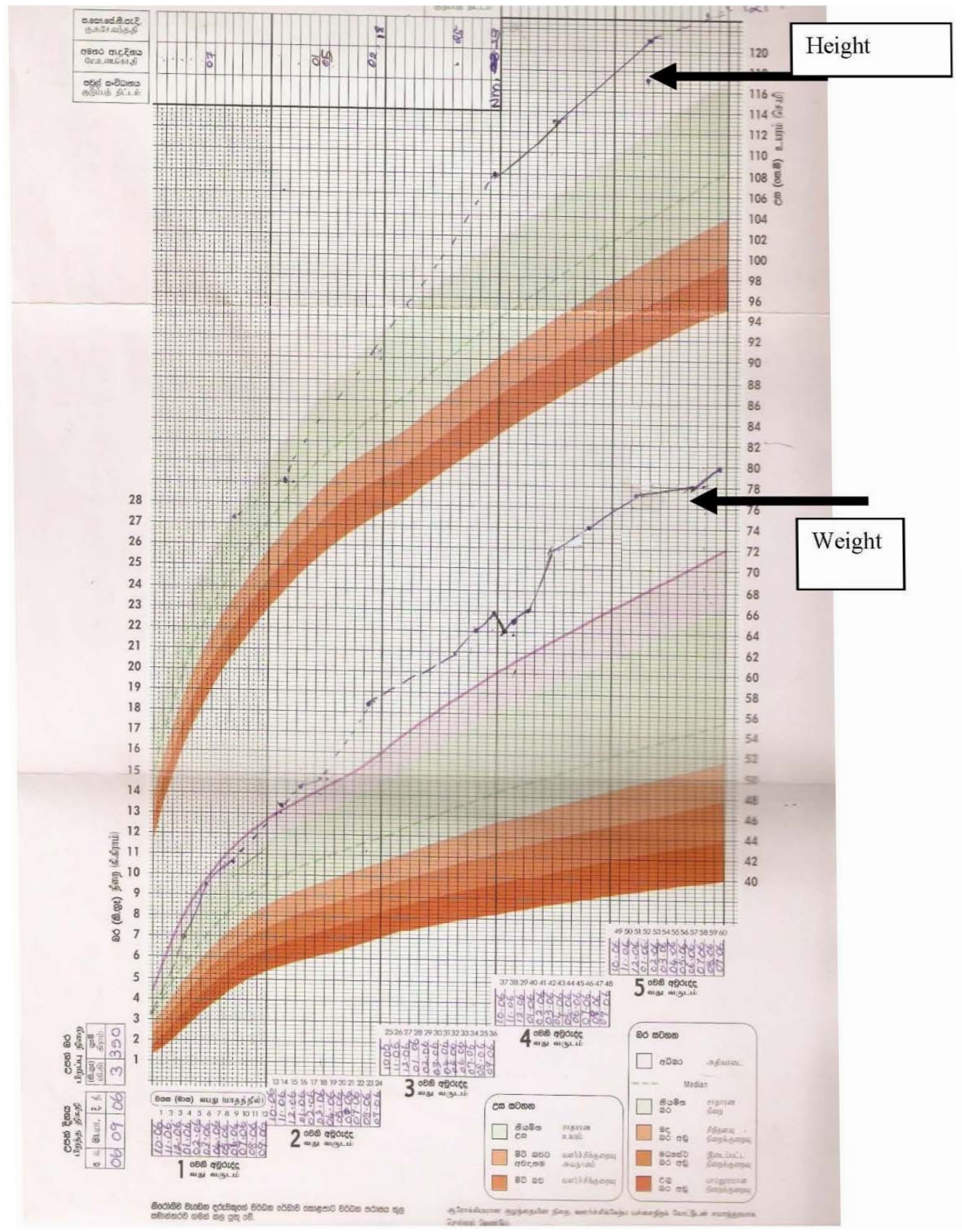

Figure 1. CHDR of the patient. 


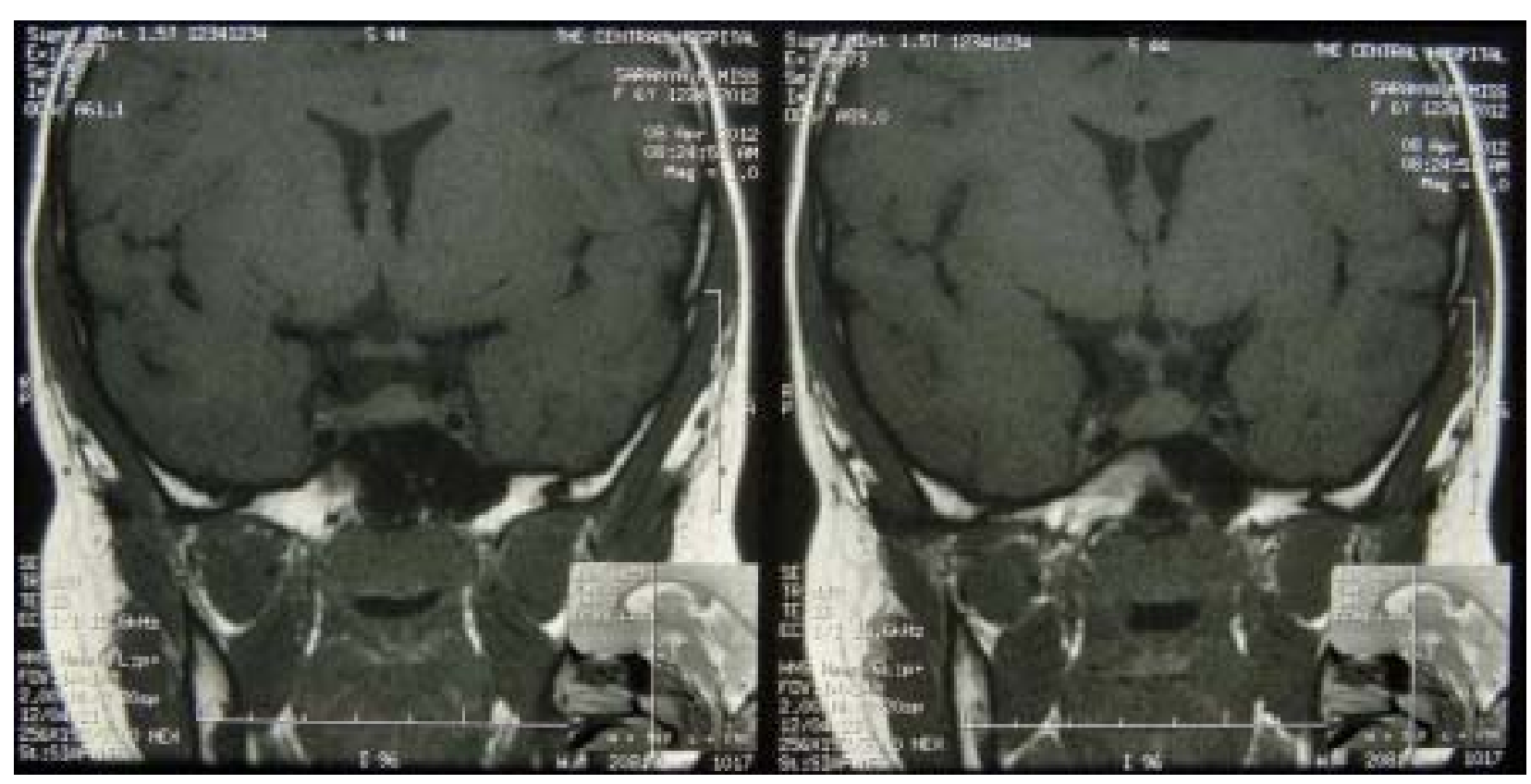

Figure 2. MRI scan of brain - (pre contrast).

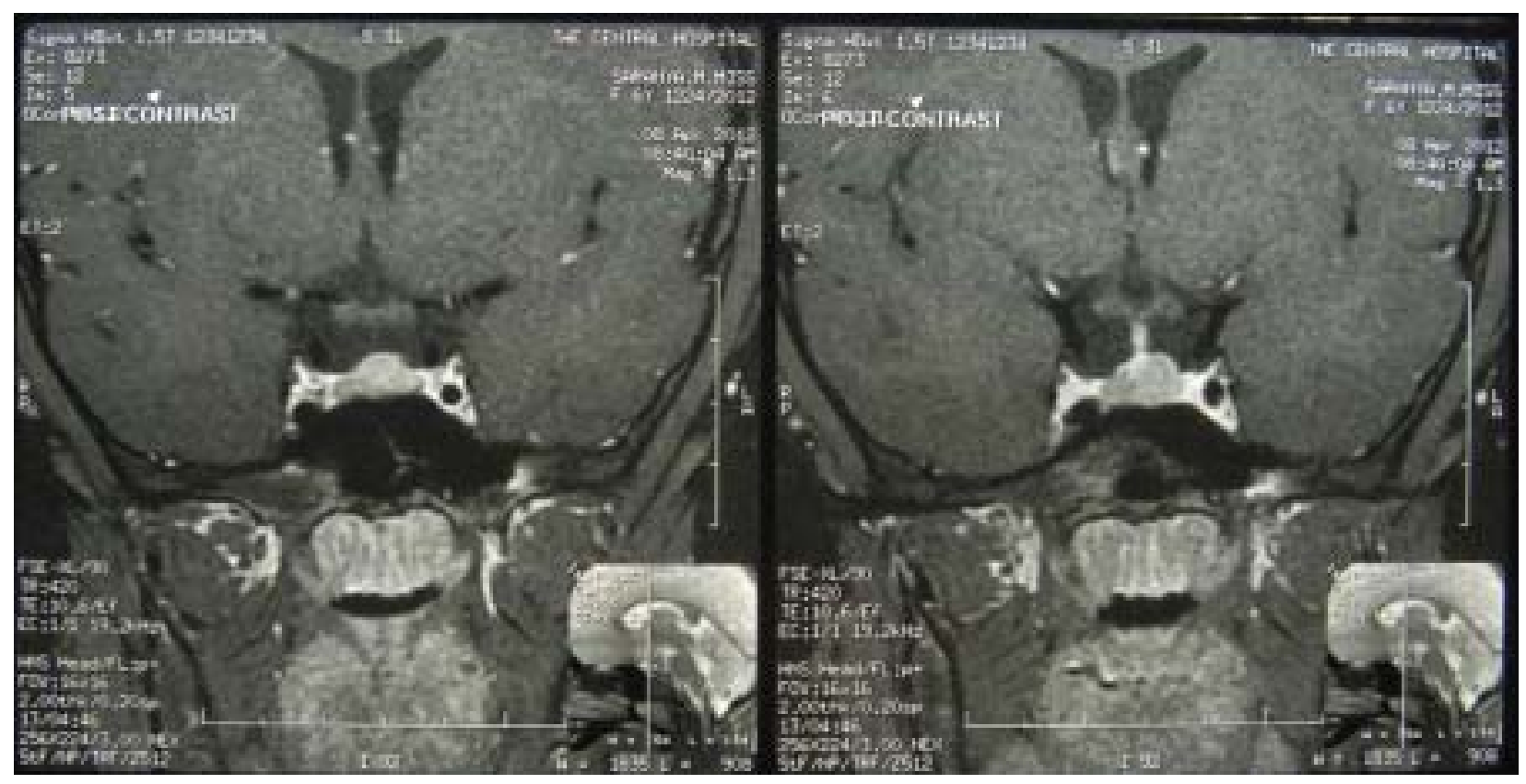

Figure 3. MRI scan of brain - (post contrast).

Table 1. Results of glucose suppressed growth hormone (GH) (75 g OGTT)

\begin{tabular}{ll}
\hline Time & Serum $G H$ \\
\hline Basal & $1.47 \mathrm{ng} / \mathrm{ml}$ \\
$1 / 2 \mathrm{hr}$ & $0.79 \mathrm{ng} / \mathrm{ml}$ \\
$1 \mathrm{hr}$ & $2.5 \mathrm{ng} / \mathrm{ml}$ \\
$11 / 2 \mathrm{hr}$ & $3.15 \mathrm{ng} / \mathrm{ml}$ \\
$2 \mathrm{hr}$ & $2.42 \mathrm{ng} / \mathrm{ml}$ \\
\hline
\end{tabular}


As the $75 \mathrm{~g}$ OGTT was inconclusive she also underwent a 9 point growth hormone $(\mathrm{GH})$ assessment, which showed a normal pulsatile secretary pattern of GH (Table 2).

Table 2 . The 9 point growth hormone assay

\begin{tabular}{lr}
\hline Time & \multicolumn{1}{c}{$G H$} \\
\hline 8 a.m. & $<1.0 \mathrm{mu} / \mathrm{L}$ \\
10 a.m. & $9.2 \mathrm{mu} / \mathrm{L}$ \\
12 noon & $1.0 \mathrm{mu} / \mathrm{L}$ \\
2 p.m. & $<1.0 \mathrm{mu} / \mathrm{L}$ \\
4 p.m. & $1.0 \mathrm{mu} / \mathrm{L}$ \\
6 p.m. & $9.9 \mathrm{mu} / \mathrm{L}$ \\
8 p.m. & $<1.0 \mathrm{mu} / \mathrm{L}$ \\
10 p.m. & $9.3 \mathrm{mu} / \mathrm{L}$ \\
12 midnight & $18.4 \mathrm{mu} / \mathrm{L}$
\end{tabular}

It has been reported that the size of the pituitary gland enlarges during puberty $(10,11,12)$. This was the reason for the MRI findings and the normal GH assay in our patient. After proper counseling of the parents it was decided to treat the patient with depot Goserelin acetate $3.6 \mathrm{mg}$ monthly. After 9 months of follow up, the child's growth stabilized with regression of breast tissue and cessation of menstruation.

\section{Discussion}

MRI is not indicated in all patients presenting with CPP (3). For healthy girls aged 6-8 years with no signs or symptoms of CNS disease, the likelihood of finding a tumor or intracerebral pathology is only about $2 \%$; therefore, this test may be unnecessary depending on the clinical situation. But among children younger than 6 years there is a greater chance of finding CNS pathology, therefore MRI is routinely indicated in these children (4).

With the recent advances, MRI has become the investigation of choice for visualizing intracranial structures including the pituitary gland. Various studies depending on MRI findings of the pituitary in different age groups, have described the dynamic changes in the size, shape and signal intensity of the pituitary in these age groups, which reflects the changes in the complex hormonal environment of this gland $(5,6,7)$. These changes were more significant in females. The height of the anteriorpituitary gland increases between birth and 15 years, with two peaks, one during the first year of life and the second during puberty. Increased secretion of LH and FSH is the main cause of increased volume of the pituitary gland at puberty. It remains unchanged until the age of 40 years, after which it decreases (8). This decrease occurs despite of an increase in gonadotrophin secretion at this age. It has also been found that pituitary volume followed the same morphological growth pattern that is reported for pituitary height. The maximum volume of the gland was achieved in the second decade of life for females and third decade for males (9).

There are also published data which have compared MRI findings of the pituitary glands of children with central precocious puberty with age and sex matched control subjects. These studies were helpful in defining MRI-derived variables in the diagnosis of central precocious puberty, and to correlate them with the hormonal profile and other imaging and clinical findings. These variables were pituitary height, length, width, midsagittal cross-sectional area, calculated volume, and shape. The shape was assessed by a pituitary grading system which was defined by the concavity of the upper pituitary surface (grade $1=$ marked concavity, grade 2 = mild concavity, grade $3=$ flat, grade $4=$ mild convexity, grade $5=$ marked convexity). The results concluded that pituitary size and shape correlated with the hormonal profile and change in pituitary grade is the most helpful variable for the diagnosis of central precocious puberty in a prepubertal child $(10,11,12)$.

\section{Conclusion}

In conclusion, this report emphasizes the need for careful interpretation of the MRI imaging before arriving at a diagnosis in patients with CPP. The normal variation of enlargement in height and volume of the pituitary gland should always be considered in the differential diagnosis of the pituitary enlargement in these patients.

\section{References}

1. Merke DP, Cutler GB. Evaluation and management of precocious puberty. Archives of Disease in Childhood 1996; 75: 269-71.

2. Lee PA, Houk CP. Puberty and Its Disorders. In: Lifshitz F, editor. Pediatric Endocrinology. New York: Informa Healthcare, 2007: 273-303.

3. Fahmy JL, Kaminsky CK, Kaufman F, Nelson Jr MD, Parisi MT. The Radiological Approach to Precocious Puberty. The British Journal of Radiology 2000; 73: 560-7.

4. Chalumeau M, Chemaitilly W, Trivin C, et al, Central Precocious puberty in girls: An evidence-based diagnosis tree to predict central nervous system abnormality. Pediatrics 2002; 109(1): 61-7.

5. Fink A M, Vidmar S, Kumbla S, et al. Age-Related Pituitary Volumes in Prepubertal Children with Normal Endocrine Function: Volumetric Magnetic Resonance Data. Journal of Clinical Endocrinology and Metabolism 2005; 90(6): 3274-8. 
6. Tien RD, Kucharczyk J, Bessette J, Middleton M. MR imaging of the pituitary gland in infants and children: changes in size, shape, and MR signal with growth and development. American Journal of Roentgenology 1992; 158: 1151-4.

7. Tsunoda O, Okuda K. Sato. MR Height of the Pituitary Gland as a Function of Age and Sex: Especially Physiological Hypertrophy in Adolescence and in Climacterium. American Journal of Neuroradiology1997; 18: 551-4.

8. Ikram MF, Shokh I, Sajjad Z, Omair A. Pituitary Height on Magnetic Resonance Imaging Observation of Age and Sex Related Changes. Journal of Pakistan Medical Association 2008; 58(5): 261-5.

9. Ikram MF, Sajjad Z, Shokh IS, Omair A. Pituitary Gland Volume On Magnetic Resonance Imaging: Normative
Observations. Pakistan Journal of Neurological Science 2007; 2(3): 141-4.

10. Sharafuddin MJ, Luisiri A, Garibaldi LR, Fulk DL, Klein JB, Gillespie KN, Graviss ER. MR imaging diagnosis of central precocious puberty: importance of changes in the shape and size of the pituitary gland. American Journal of Roentgenology 1994; 162: 1167-73.

11. Kao SC, Cook JS, Hansen JR, Simonson TM. MR imaging of the pituitary gland in central precocious puberty. Pediatric Radiology 1992; 22(7): 481-4.

12. Pfirignon F, Brauner R, Argyropoulou M, Brunelle F. Precocious Puberty in Girls: Pituitary Height as an Index of Hypothalamo-Pituitary Activation. Journal of Clinical Endocrinology and Metabolism 1992; 75(4): 1170-2. 